\title{
Infrastructural Development of Energy Planning and Energy Management for Smart Grid Implementation
}

\author{
Seema Arora ${ }^{1}$, Pawan Kumar ${ }^{2}$ \\ ${ }^{1,2}$ (EEE Department, Galgotias College of Engineering and Technology, India)
}

\begin{abstract}
A growing increase in the purchase of electric appliances in turn has resulted in growing demand of energy in households, small offices, shops, academic institutes and even industries. Inefficient use of these appliances and energy consumption patterns and habits causes a waste of energy. There is an arising need to study the importance of energy feedback to inform the users on their behavior, leading to a reduction of this energy wasting behavior. The utilities need to implement demand side management and lay down pricing schemes motivating consumers to learn and adapt to personal control over usage of appliances thus resulting in energy saving. The top managements of the organizations need to frame energy policies to reduce increasing pressures on energy resources. The paper provides an overview of the main research efforts that are to be carried out in the direction to enable the consumer make judicious and wise use of appliances and energy patterns and contribute in smart grid implementation plans by playing a vital role.
\end{abstract}

Keywords: Smart Grids, Smart appliances, Automated Metering Infrastructure, Energy Demand Management, Perceived Personal Control

\section{INTRODUCTION}

The smart grid is defined as the set of advanced, digitally based technologies that can be attached at the boundary of generation and transmission and all the way through the grid to the distribution level, till the meter at the customer premises and into the home as well. The past decade has been pivotal in the power industry for broadening the definition of smart grid from Automated Meters (AMRs) to Automated Metering Infrastructure (AMI) to encompass a larger set of applications which include centralized and integrated voltage and volt amperes reactive (VAR) controls, grid automation, advanced monitoring and diagnostics as well as AMI The drive is to combine communications, digital technology and hardware, and decision making to drive improvements in cost, service, reliability, and quality of supply [1].

The emerging issues include creating distributed management (DM) through using distributed intelligence and sensing; integration of renewable resources; use of active-control high-voltage devices; developing new business strategies for a deregulated energy market; and ensuring system stability, reliability, robustness, and efficiency in a competitive marketplace and carbon-constrained world. In addition, the electricity grid faces following major challenges are its organization, technology readiness, road mapping of implementation plans, technical ability to meet ever increasing electricity needs, ability to increase its efficiency without diminishing its reliability and security. Demand Side Management (DSM) is one of the key components of smart grid implementation plan and refers to managing the demand for power by utilities among some or all the consumers to meet their current or future needs with the primary aim focused on demand reduction.

The objectives of work carried out is to provide: (a) An experience feedback on energy efficiency policies and measures focused on growing demand of energy in households, small offices, shops, academic institutes and even industries, (b) Inefficient use of these appliances and energy consumption patterns and habits causes a waste of energy; consumers need to focus on demand side management, special incentive schemes have to be designed and rolled off by the tariff collection agencies involved and (c) Recommendations for future policies and measures.

The research also aims to explain how the framework can be used by utilities strategically to design, roll out, and communicate with consumers about the smart grid.

\subsection{Smart Metering}

\section{SMART TECHNOLOGY}

The smart meter refers to electric meters which keep detailed statistics on usage and will provide the means of communication between consumers and the utilities. This will enable the integration of other technologies such as demand response. Real-time consumption level data can be transferred to the utilities, and will enable the consumers to monitor their electricity consumption and take measures to reduce their usage and also save on money. Additionally, smart meters can be easily installed, give accurate readings, provide real time pricing of the electricity or indirect load control known as dynamic price response. The consumption can be monitored/ controlled through mobile or internet $[1,2]$. 


\subsection{Smart Appliances}

The so-called smart appliances are designed to work within smart energy grids. Smart appliances are becoming a substantial component of the residential demand response capabilities of the smart grid. Next generation of home appliances now have the ability to receive, interpret, and act on a signal received from a utility, then automatically adjust their operation to save energy or perform other functions, according to research from SBI Energy [4, 5, and 6].

A necessity for the implementation of these applications is the availability of a smart meter in the house or place of their usage. Air conditioners, refrigerators, freezers, washing machines, dish washers, clothes dryers, electric ovens and microwaves are amongst the most energy consuming appliances used in households. Smartness in technology can help reducing their energy use. An example of the application of smart technology is the possibility to partly or completely switch off an appliance during its runtime without any noticeable consequences for the consumer. If the energy used in homes by air conditioners or refrigerators is cut down for short intervals, it will not bring any noticeable consequences. More generally, in all appliances that need energy, but are flexible in terms of the moment at which this energy is delivered, this kind of technology can be integrated.

Washing machines, alongside the adoption of home energy management systems are the leading segment for smart appliances and will likely have the greatest return on investment (ROI) of all consumer smart products because of their intermittent use and ability to time defer use during off-peak hours. The predicted momentum could take a couple of years due to the high price of smart appliances; consumer demand should increase once prices come down.

\subsection{Smart Pricing Schemes}

DSM allows end users to better manage their load curve by offering user-friendly and energy-friendly pricing schemes as listed:

\subsubsection{Time of Use (ToU) tariff}

This scheme encourages consumers to shift their consumption from a peak- to off-peak period. This is a non-dynamic tariff, and in fact large scale integration of such a tariff may in turn just simply shift the peak time.

\subsubsection{Real-Time Pricing (RTP)}

The price of the electricity in the market changes hourly (or half an hourly in some markets). It offers a type of tariff which changes hourly to reflect the variations in supply and demand and the price of the electricity in the market. It provides incentives to consumers to limit their consumption when the wholesale price of the electricity is high and increase their consumption at lower electricity price periods.

\subsubsection{Coincident Peak Pricing (COP) or Critical Peak Pricing (CPP)}

Another reasonable alternative is critical-peak pricing (CPP). CPP tariffs augment a time-invariant or TOU rate structure with a dispatchable high or "critical" price during periods of system stress. The critical price can occur for a limited number of discretionary days per year, or when system or market conditions meet predefined conditions. Participating customers receive notification of the dispatchable high price, typically a day in advance, and in some cases are provided with automated control technologies to support efficient load drop. Since, all of the prices in a CPP rate are preset, CPP is not as economically efficient as RTP; this same characteristic, however, also makes CPP politically more appealing, because it diminishes the potentially large price risk associated with RTP.

\subsection{Smart Buildings}

Energy Conservation Building Code (ECBC) has been developed to deal with rapid increase in energy consumption by commercial buildings, especially in urban and sub-urban areas. ECBC has set standards for design and construction so as to encourage energy efficient designs [5, 7, and 8]. The general procedure to establish an EDM program in buildings involves [9]:

- Review historical energy use;

- Perform energy audits;

- Identify energy management opportunities;

- Implement changes to save energy;

- Monitor the energy management program,;

- Review progress. 


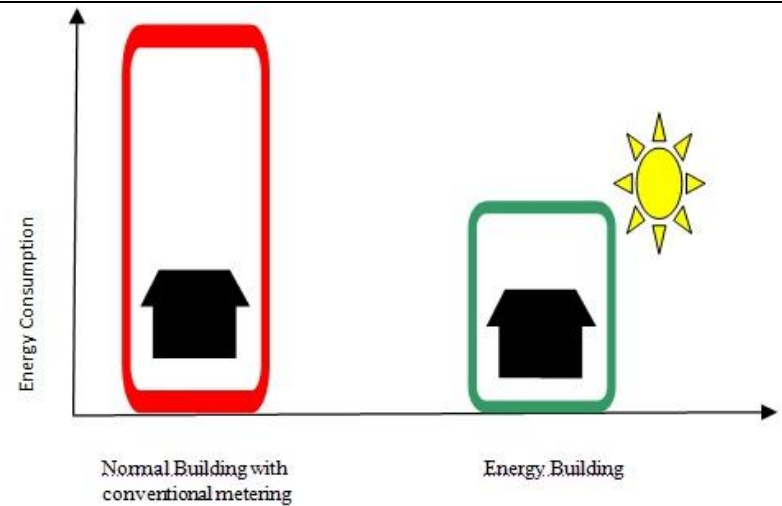

Fig.1. Typical Energy Consumption for a normal Building and for an Energy building

III.

SMART INFRASTRUCTURE

A smart grid is made possible by robust, end-to-end communications technologies. These technologies, working alongside the electrical grid, pull in data from all over the grid.. Fig. 2 shows a typical infrastructure needed for smart grid apart from existing infrastructure. Sensing devices are placed throughout the electrical grid and in consumers' homes and businesses. Information from the devices is sent to applications that can read and act upon the data. The sensors send alerts about problems, grid performance statistics, status updates and more. Utility applications absorb the data, interpret it and help utility personnel make better decisions regarding the delivery of electricity. Sensors are needed to be integrated in the network to sense the fluctuations and disturbances and give appropriate signals for isolating such areas. Smart appliances have the ability to switch themselves off in the state of frequency fluctuations. Storage devices offer the facility of energy storage for the energy generated at off peak hours and usage at peak hours. The rise of the hydrogen fuel system, especially as an energy storage system, will enable grids to store large amounts of energy locally [3, 4, and 9].

Such systems have been analyzed academically. The impact of such systems is not yet understood to complete the analysis of reliability and of economic viability. Automated processes at substations, faster routing around outages, smart meters in homes and other improvements will benefit everyone with a stronger, more flexible grid. Processors help in execution of protection within microseconds of fault identification. Demand Management (DM) and Demand Response (DR) imply that the industry needs to include the consumer in the long-term solution of the rising consumption and limited resources problem. The installation of distributed generation, especially solar and wind is an indication of a new industry organization. Several utilities, recognizing this trend, are already responding accordingly.

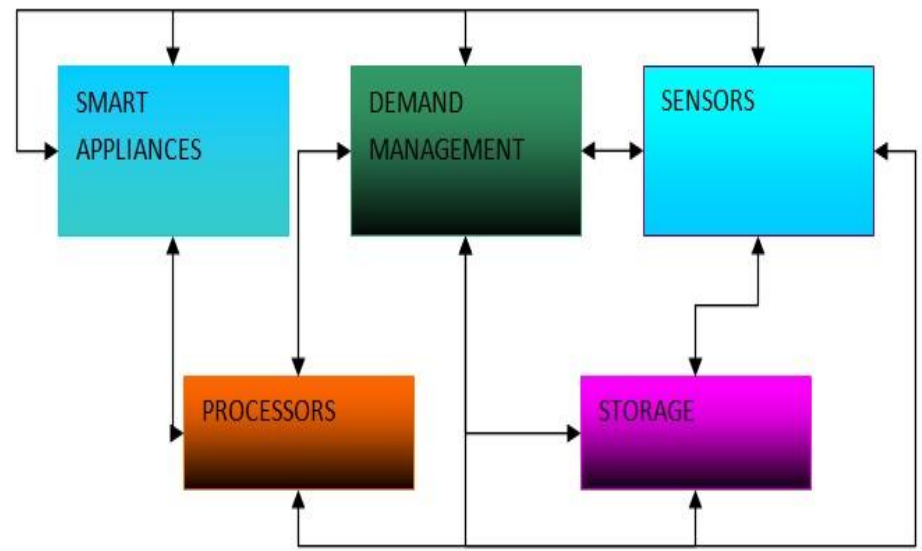

Fig.2. Typical Infrastructure Needed For Smart Grid

In order to reduce the electrical energy costs, sometimes, it could be possible to implement an Energy Demand Management (EDM) program, which is the use of financial incentives, education or other programs to modify the demand for energy. One of the characteristics of EDM program is to encourage users to reduce the load at peak times or move the time (to off-peak times) that load is used, such as night-time or weekends [7]. The various steps in energy action planning are indicated in the Fig. 3 which depict that planning is one of the most important components of Energy Management program in any building. 


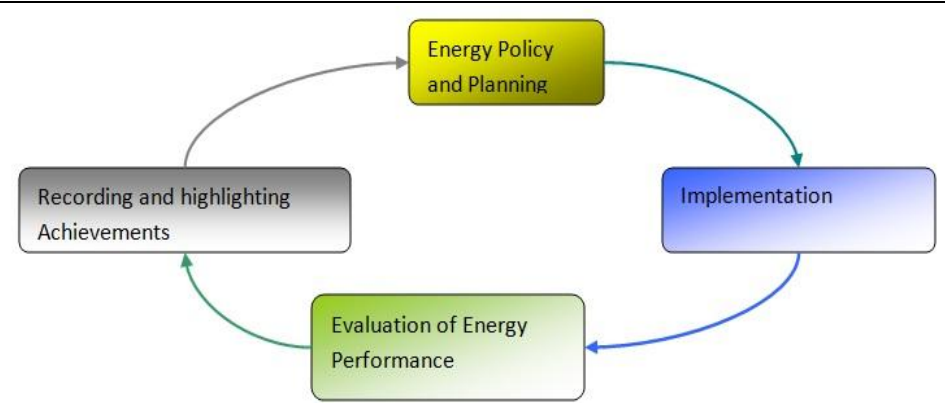

Fig. 3. Energy Plan Action.

\subsection{Energy saving actions}

Typically in office buildings, heating systems and lighting, dominate electricity use, furthermore, computers and other office equipments such as printers, copiers, scanners and facsimile machines are becoming an important electric energy-use devices. It is one thing to know about different activities that can lead to a more efficient use of energy, but knowledge alone does not ensure right actions. Several utilities across the world have performed field studies, which indicate a major waste of electricity in low-income households. Among the most important reasons, they found: lack of information about its rational use, leading to waste; precarious electrical installation; use of inefficient refrigerators; and buildings without ventilation and natural lighting.

\subsection{Survey Questionnaire}

The researchers have carried out a statistical analysis (In a Residential urban as well as rural area of a small city of Greater Noida) and asked the respondents (100 for each area) to provide information about what they had actually done themselves to use energy more efficiently [Fig. 4].

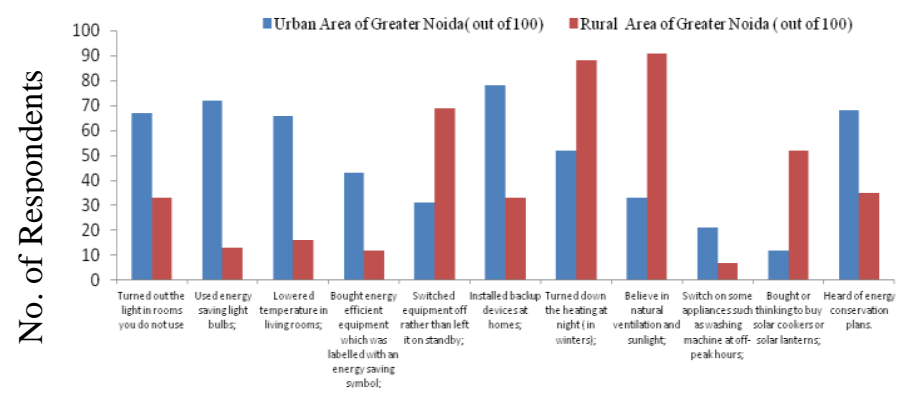

Fig. 4. Statistical analysis (In a Residential area of a small city of Greater Noida)

The report reveals that people seem to know about activities that they are engaged with, but it cannot be concluded that there is correlation between knowledge and action at this stage of the analysis. It may be more likely that the question was either not interpreted well or two questions were understood as similar during the process of the survey. It included the set of questions such as turned out the light in rooms you do not use, used energy saving light bulbs, lowered temperature in living rooms, bought energy efficient equipment which was labeled with an energy saving symbol, switched equipment off rather than left it on standby, installed backup devices at homes, turned down the heating at night (in winters), believe in natural ventilation and sunlight, switch on some apparatus at off peak hours, bought or thinking to buy solar cookers or solar lanterns, heard of energy conservation plans.

\subsection{Discussion on Statistical analysis}

The results of the survey reveal that rural respondents naturally respond to reduced consumption in some actions such as switching equipment off rather than leaving on standby, turned down heating at night and believe in natural ventilation and lighting in comparison to their urban counterparts. In contrast, urban respondents have outweighed in number in energy efficient actions such as using energy saving light bulbs, purchasing energy efficient equipment, turning off the lights when not occupying although the response could be made far better if trained for energy conservation. The other goal of this analysis was to establish a sociocultural framework for analyzing the knowledge and attitudes of people of this area on energy saving. 


\section{FUTURE ENERGY POLICY ACTION}

Building awareness in small and big corporate offices, college campus, industries, utilities, top managements and staff of the organizations need to emphasize on the action plans and meet the laid objectives.

\subsection{Top Management Action Plan}

- Gives attention to energy conservation, frames an energy conservation policy and announces it to its employees;

- Extends whole hearted support to energy conservation team and actions proposed by it;

- Declares timely incentives to team members who succeed in energy conservation projects;

- Announces results of energy conservation to all the employees;

- Get feedback and suggestions from all concerned about the policy plan and evaluation process and improves plan if necessary;

- Organize in house training and seminars by qualified speakers and energy policy makers.

\subsection{Staff Action Plan}

Even individuals working in or managing a facility may have little understanding of the energy performance indices of the facility being used. For awareness, the following information may be gathered before starting the work:

- Overall energy costs, operating cost of the equipment;

- Energy performance of equipment or processes involved.

In addition, staff needs to emphasize on the following listed practices:

- Be responsive to energy cut down action plan;

- Develop new skills in energy saving technologies ( in-house and outside training);

- Adopt new attitudes towards energy wastage and reduction of waste;

- Give suggestions or methods to implement energy saving measures.

\subsection{General objectives of the Utilities}

The utilities also need to strategically design, roll out, and communicate with consumers about the smart grid. They can include the following general objectives:

- Improving life conditions of the low income households and favoring their integration into the society;

- Reducing the subsidies due to the social tariff while empowering to cover their electricity bills, by reducing their energy consumption levels thanks to energy efficiency improvements;

- Reducing illegal connections, both for improving housings' safety and for decreasing commercial losses incurred to the utilities;

- Reducing collection expenses (due to unpaid bills, disconnection, etc.);

- Increasing revenues while improving the reliability of electricity supply by reducing peak load demand.

\subsection{Operational objectives of the utilities}

- Mini-audits of households /offices/ commercial places to identify energy efficiency opportunities, particular assessing the need to replace inefficient refrigerators and unsafe internal wiring ;

- Replacing inefficient electric showerheads in households by more efficient ones or by solar water heaters;

- Replacing low energy efficiency incandescent bulbs by highly energy efficient Compact Fluorescent Lamps (CFLs);

- Education and information (especially about a safe and regular use of electricity);

- Educating the users towards energy saving and energy efficiency;

- Arrange interactive meets between energy managers, energy auditors, consumers and smart grid or Energy Management experts.

The "Bachat Lamp Yojna" in India aims at large scale replacement of inefficient incandescent bulbs in households by highly energy efficient CFLs. The scheme seeks to replace estimated 400 million incandescent bulbs by CFLs which could save 6000 MW by 2012 [5].

\section{CONCLUSION}

Creating a smart grid is no longer a distant idea; it is already in the process of being a reality. But considerable technical challenges as well as several economic and policy issues remain to be addressed. Funding and sustaining innovations remain a challenge as utilities must meet many competing demands on precious resources while trying to be responsive to the consumer needs. 
Infrastructural Development of Energy Planning and Energy Management for Smart Grid

It is very unlikely that initiatives in energy efficiency would have taken place without the regulators' enforcement. However, provisions in legislation alone are not sufficient condition to ensure that resources are being used efficiently to maximize the public interest of energy-related services.

The environmental push to drive energy efficiency, integrate large amounts of intermittent large-scale renewables as well as distributed generation has stimulated serious interest in ensuring the future grid is well equipped to accommodate this need. AMI-enabled demand response has also assumed a critical role in the discussion of finding least-cost alternatives to new build or expensive power purchases. While direct load control without AMI will continue as an important building block for demand response, introducing consumer decisions to reduce usage will provide necessary additional load reduction. Customer awareness will continue to grow if proper energy management awareness programs are conducted among the masses and the seriousness of energy problem and its impact on the economic growth of the country is demonstrated.

\section{REFERENCES}

[1] Schisler, K.; Sick, T.; Brief, K., "The role of demand response in ancillary services markets," Transmission and Distribution Conference and Exposition, 2008. T\&D. IEEE/PES, vol., no., pp.1-3, 21-24 April 2008.

[2] The business scenen leader or follower developing the smart grid business casei IEEE, November / December 2008

[3] Smart washing machines leading smart appliances globally, http://www.fiercesmartgrid.com, /2012-07-25.

[4] Laurence Hauttekeete, Jeroen Stragier, Wouter Haerick and Lieven De Marez, "Smart, smarter, smartest... the consumer meets the smart electrical grid", 2010 IEEE.

[5] Energy Conservation Act 2001, India and related Policies.

[6] In my view what about U. S.? Deregulated electric power market economics.

[7] A.F. Orlando, M.P. Málaga, M.M. Huamani, "Methodology for generating electric load profiles for sizing an electric energy generation system," Proc of Energy and Buildings 52 ,2012, pp. 161-167.

[8] Pieter de Wilde, Marinus van der Voorden, "Providing computational support for the selection of energy saving building components," Proc of Energy and Buildings 36, (2004, pp. 749-758.

[9] K. Frank, D. Goswami Yogi,, “Energy Management and Conservation Handbook”, CRC Press, United States, 2008. 